\title{
ESTUDO TIPOLÓGICO SOBRE A FORMA URBANA: CONCEITOS E APLICAÇÕES
}

\author{
CONCEPTS, APLICATIONS AND URBAN FORM: A STUDY OF TYPES
}

\author{
AMORIM, Flávia Pereira \\ Mestranda PROARQ/FAU_UFRJ, arquiteta do ETU/UFRJ. E-mail: flaviamorim@gmail.com \\ TANGARI, Vera \\ Profa. Dra. FAU-PROARQ/UFRJ. E-mail: vtangari@uol.com.br
}

\section{RESUMO}

Este trabalho visa à conceituação de tipologia morfológica como instrumento de pesquisa na análise da paisagem urbana. Em um primeiro momento discorremos sobre os conceitos tipologia e morfologia segundo teóricos como Quatremère de Quincy, Giulio Carlo Argan, Aldo Rossi e Rob Krier, e ainda, José Lamas e Josep Montaner. Em um segundo momento discorremos sobre o conceito de tipologia morfológica, uma análise da paisagem que associa o instrumento de pesquisa da tipologia ao da morfologia. Para finalizar é apresentado um exemplo de aplicação desta análise num recorte da cidade de Belo Horizonte, Minas Gerais.

\section{Palavras-chave: Paisagem urbana, belvedere, tipologia, morfologia.}

\begin{abstract}
This paper work attempts to a conceituacion of morphological typology as an instrument of research on the analysis of the landscape. In a first moment we will talk about concepts of typology and morphology of Quatremère de Quincy, Giulio Carlo Argan, Aldo Rossi e Rob Krier, e ainda, José Lamas e Josep Montaner. In a second moment we will say about the concept of morphological typology, an analysis of the landscape that associates the instrument of research of typology and morphology. To and the discussion an example of application of this analysis is shown in a study of the city of Belo Horizonte, Minas Gerais.
\end{abstract}

Key words: Urban landscape, belvedere, typology, morphology.

\section{1 - Introdução}

Este trabalho é parte integrante da conceituação teórica da metodologia de análise da paisagem adotada na dissertação de mestrado da autora e foi apresentado como trabalho final da disciplina de Pensamento Arquitetônico Contemporâneo II, do curso de pós-graduação da Faculdade de Arquitetura da UFRJ, PROARQ-UFRJ.

Ao se estudar a arquitetura da cidade podemos identificar os diversos elementos formadores da paisagem urbana', seus tipos, sua evolução ao longo dos anos, sua composição na forma da cidade, a influência que sofrem da cultura, economia e história, da formação morfológica do sítio urbano em que se inserem, entre outros fatores.

As ferramentas de pesquisa que possibilitam esta análise são a tipologia, estudo dos tipos, e a morfologia urbana, estudo das formas urbanas, que, associadas, constituem um método de análise da morfologia da paisagem urbana, que pretendemos estudar a seguir.

Com os conceitos definidos por autores como Quatremère de Quincy, Giulio Carlo Argan, Aldo Rossi e Rob Krier, e ainda, José Lamas e Josep Montaner foram estabelecidos os critérios de análise do bairro Belvedere, em Belo Horizonte, área recorte estudado pela autora, apresentaremos a seguir as considerações encontradas e a representação gráfica da avaliação do bairro seguindo a metodologia em estudo. 


\section{2 - Conceituação}

Segundo Rossi, tipologia construtiva e morfologia urbana têm uma relação dialética, onde a forma urbana é interdependente da forma construtiva e trabalhar a forma urbana é determinar tipologias. A cidade portando é o princípio ordenador no qual se desenvolvem e estruturam os tipos construtivos que integrarão a forma urbana ${ }^{2}$. Fazendo-se necessário, portanto, o estudo dos tipos construtivos e da morfologia urbana para o entendimento da paisagem urbana.

\section{1 - Tipologia}

No campo da arquitetura, o estudo (logia) dos tipos, através da sistematização dos caracteres arquitetônicos nos séculos XVIII e XIX, representou a análise de projetos ideais. Quatremère de Quincy em sua definição de tipo afirma que "(...) o modelo, entendido segundo a execução prática da arte, é um objeto que se deve repetir tal qual é; o tipo é, pelo contrário, um objeto segundo o qual qualquer pessoa pode conceber obras que não se assemelharam em nada entre si. Tudo é preciso e dado em um modelo; tudo é mais ou menos vago no tipo. Assim vemos que a imitação dos tipos nada tem que o sentimento e o espírito não possam reconhecer (...)" 3 .

Com esta definição, Quincy evidencia a diferença entre tipo e modelo ressaltando que no tipo existe possibilidade de adequação ao meio - "tudo é mais ou menos vago" - e ainda, que um mesmo tipo pode gerar uma grande diversidade de formas - "obras que não se assemelham em nada entre si".

Em 1960 o conceito de tipo arquitetônico foi retomado e disseminado como base para a concepção de conjuntos habitacionais, condicionados aos tipos de edificação preconizados pelos CIAMS e Carta de Atenas. Neste contexto Giulio Carlo Argan retoma o conceito de Quincy, defendendo que o estudo tipológico não significa atribuição de valor a exemplos de arquitetura que se aproximam do ideal, nem representa um tipo de classificação ou estatística. Estudos de tipologia arquitetônica são, na verdade, formados e transmitidos pela literatura e pela prática como uma analogia formal e funcional da construção histórica e cultural, em resposta a exigências ideológicas, religiosas ou práticas de uma série de exemplares. Para ele a arquitetura é composta de formas carregadas de simbolismo que se constituíram através dos anos.

Argan defende, ainda, que o tipo é um esquema reduzido de um conjunto de variantes formais a uma forma-base comum, um fundamento constante, histórico, suscetível a variantes, que resultam em um caráter particular; e pode ser identificada por funções práticas - hospitais, escolas, bancos - e configurações - planta central, longitudinal, etc.

Segundo o autor, o esquema tipológico está relacionado à manifestação da experiência histórica no traçado projetual e oferece fundamentos para a definição formal apresentando um conjunto de noções comuns ou um patrimônio de imagens, com seus conteúdos ou significados ideológicos.

Na procura por uma alternativa ao movimento moderno, estudos de tipologia edilícia são retomados por Rossi, Aymonino, Muratore, Caniggia, Panerai, entre outros. Rossi defende a idéia de que arquitetura não é copia nem imitação, os princípios arquitetônicos são únicos e imutáveis, e as respostas a situações concretas, situações humanas, dadas a questões diversas, são múltiplas. Neste contexto, o tipo é uma constante formada por características necessárias e universais, antecipa soluções e não existe antes da arquitetura, mas pelo contrário é o resultado da mesma ao longo dos anos ${ }^{4}$.

Para Rossi o tipo vai se constituindo de acordo com as necessidades. É único e variado em diferentes sociedades, está diretamente ligado à forma e ao modo de vida: é algo permanente 
e complexo, existe antes da forma e a constitui. Rossi diz ainda que nenhum tipo se reduz à forma, mesmo sendo todas as formas arquitetônicas redutíveis a tipos. O tipo é, para Rossi, uma constante que recebe influência da técnica, da função, da estética, do caráter coletivo e do momento individual do fato arquitetônico ${ }^{5}$.

\section{2 - Morfologia}

O estudo (logia) das formas (morfo), neste caso é adotado como o estudo das formas da cidade. Em seu texto "Consideraciones sobre la morfologia urbana y la tipologia contructiva", Rossi considera, no estudo das formas da cidade, os sistemas funcionais geradores do espaço urbano e a cidade como uma estrutura espacial. Dentro dos sistemas sociais distingue o econômico, o político e o social. Na estrutura espacial ou paisagem urbana, a morfologia, para Rossi, deve ser vista sob três escalas: da rua, do bairro e da cidade ${ }^{6}$.

Rossi considera a edificação um dos elementos fundamentais da paisagem urbana, podendo assumir diferentes funções e representa a área construída do solo. Rossi cconsidera que ao analisarmos o espaço na escala do bairro temos conjuntos com características comuns. Um bairro é caracterizado por um critério social baseado em um principio de divisão de classes e de funções econômicas. $O$ bairro, portanto, está caracterizado por uma determinada paisagem urbana, conteúdo social e função própria.

Partindo da unidade da escala da rua e do bairro, a escala da cidade pode ser entendida como um conjunto de bairros. Por meio do estudo morfológico das cidades podemos identificar os agentes que interferem diretamente na constante evolução urbana e Rossi atribui ao fator econômico, por meio da especulação imobiliária, a principal razão de transformação da cidade.

Para Rossi nenhum empreendimento nas cidades capitalistas se justifica sem lucro, as intervenções urbanas só são realizadas por viabilizarem o desenvolvimento econômico da cidade. Ele cita o estudo sobre o uso do solo em Paris, de Maurice Halbawachs, segundo o qual, o projeto de Hausmann para Paris não teria sido implantado apenas com as razões de ordem, de higiene e de estética, se não resultassem em um avanço econômico importante.

Seguindo a mesma linha de conceitos de Rossi, Lamas, em seu livro Morfologia urbana e o desenho da cidade, afirma que a forma da cidade é resultante de fatores socioeconômicos, políticos e culturais e a arquitetura é a forma do espaço humanizado. A forma, para Lamas, é determinada ainda por concepções estéticas, ideológicas, culturais ou arquitetônicas, além do comportamento, utilização do espaço e vida comunitária dos cidadãos, o que faz da forma urbana uma estrutura física e funcional ${ }^{7}$.

Ainda segundo Lamas a morfologia urbana estuda a configuração e a estrutura exterior de um objeto, estuda as formas e seus fenômenos de origem. Lamas aponta e conceitua as mesmas escalas de Rossi, para a análise da forma na dimensão urbana: da rua, do bairro e da cidade.

A analise morfológica, para Lamas, passa pelos seguintes elementos: o solo, o lote, o edifício, o quarteirão, a fachada, o logradouro, o traçado, a praça, o monumento, a vegetação, o mobiliário urbano e os perfis viários.

\section{3 - Análise tipo-morfológica: Bairro Belvedere, Belo Horizonte}

\section{1 - Escala da cidade: evolução histórica e caracterização}

Ao associarmos na análise da paisagem urbana os conceitos de tipologia construtiva e morfologia urbana, teremos um estudo tipo morfológico que nos permite identificar os agentes formadores 
da cidade e os tipos edilícios resultantes destes fatores, nos possibilitando compreender a dinâmica de evolução urbana.

A aplicação da metodologia no bairro Belvedere em Belo Horizonte, contemplou a análise da volumetria construída, dos espaços livres, do suporte físico, e dos padrões de parcelamento, apresentados a seguir em forma de mapas e textos analíticos:
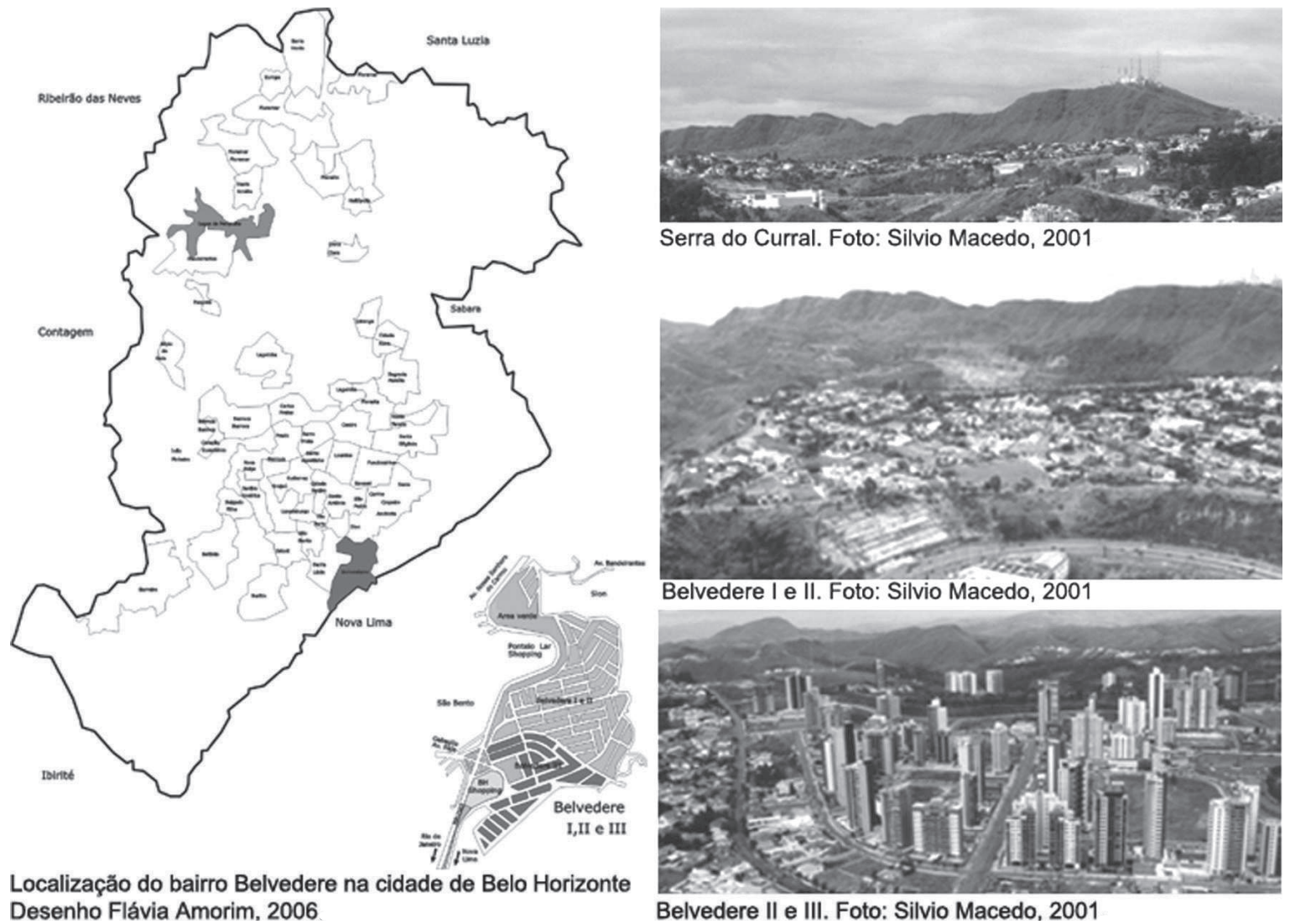

Serra do Curral. Foto: Silvio Macedo, 2001

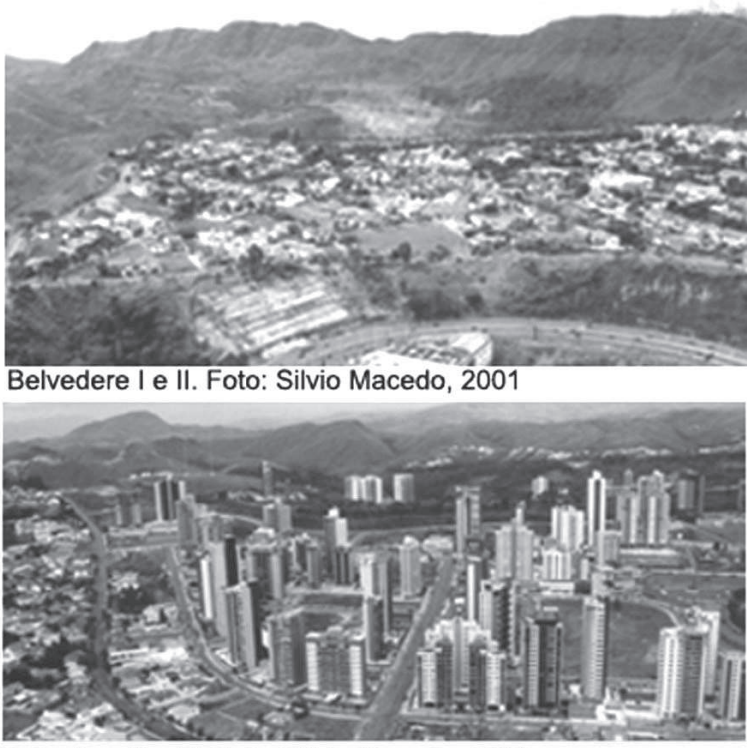

Belvedere II e III. Foto: Silvio Macedo, 2001

Figura 1: Localização e caracterização do bairro Belvedere

A área do recorte corresponde a um bairro da zona sul de Belo Horizonte, localizado no limite da cidade, aos pés da Serra do Curral, importante bem natural da capital mineira. Sua ocupação teve início em 1970. Em 1976 a Lei de Uso Solo classificou a área como ZR-2, zona residencial 2 , restringindo a ocupação a residências unifamiliares.

Os loteamentos apresentavam dimensão média de $15 \times 30 \mathrm{~m}$ e com casas em geral de 2 pavimentos e de $300 \mathrm{~m}^{2}$ de área. Outra característica comum é a presença de áreas de lazer, em grande parte das casas com piscina, sauna, quadra esportiva, churrasqueira, entre outros equipamentos.

Um novo impulso para ocupação da área mais próxima ao Shopping e ainda não parcelada se deu em 1988, criando um novo parcelamento, que depois de uma longa disputa judicial, obteve autorização da prefeitura para verticalização, alterando o zoneamento existente para ZC-3, zona comercial 3, um zoneamento comércio e até indústrias de pequeno porte.

O bairro foi parcelado loteado e vendido, mas as obras só tiveram início em 1998, depois de mais interpostos judiciais, com lotes de em média $1.000 \mathrm{~m}^{2}$ podendo chegar a $3.000 \mathrm{~m}^{2}$ por meio de remenbramento. Os edifícios apresentam em média 18 pavimentos e áreas de lazer completas, com quadras esportivas, piscinas, salão de festas, parques infantis, entre outros equipamentos. 
O bairro Belvedere avança sobre a serra do Curral, bem tombado em 1960 pelo IPHAN, Instituto de Patrimônio Histórico e Paisagístico Nacional; elemento de identidade da capital mineira que agrega valores naturais de preservação ambiental e paisagística, a serra está inserida em uma área de importante papel no equilíbrio ecológico da região, área onde se localiza parte dos lençóis freáticos que abastecem as nascentes da RMBH.

\section{3 - Na escala do bairro: análise morfológica do recorte}

Ao analisarmos morfologicamente o bairro Belvedere produzimos alguns mapas apresentados a seguir que expressam os diferentes tópicos de análise.

O primeiro mapa apresentado reflete a dinâmica diferenciada de usos e fluxos da área ao compararmos a ocupação mais antiga e a mais recente. Analisando-se os usos, apenas na área de ocupação mais recente encontramos uso misto e comercial, que se desenvolvem ao longo da Avenida Luiz Paulo Franco, principal avenida do bairro, via arterial que faz continuidade com a estrada de Nova Lima, ligando o bairro a BR 040, e em parte da Rua Juvenal Melo Senra, rua paralela a Avenida Luiz Paulo Franco e lindeira à Praça da Lagoa Seca.

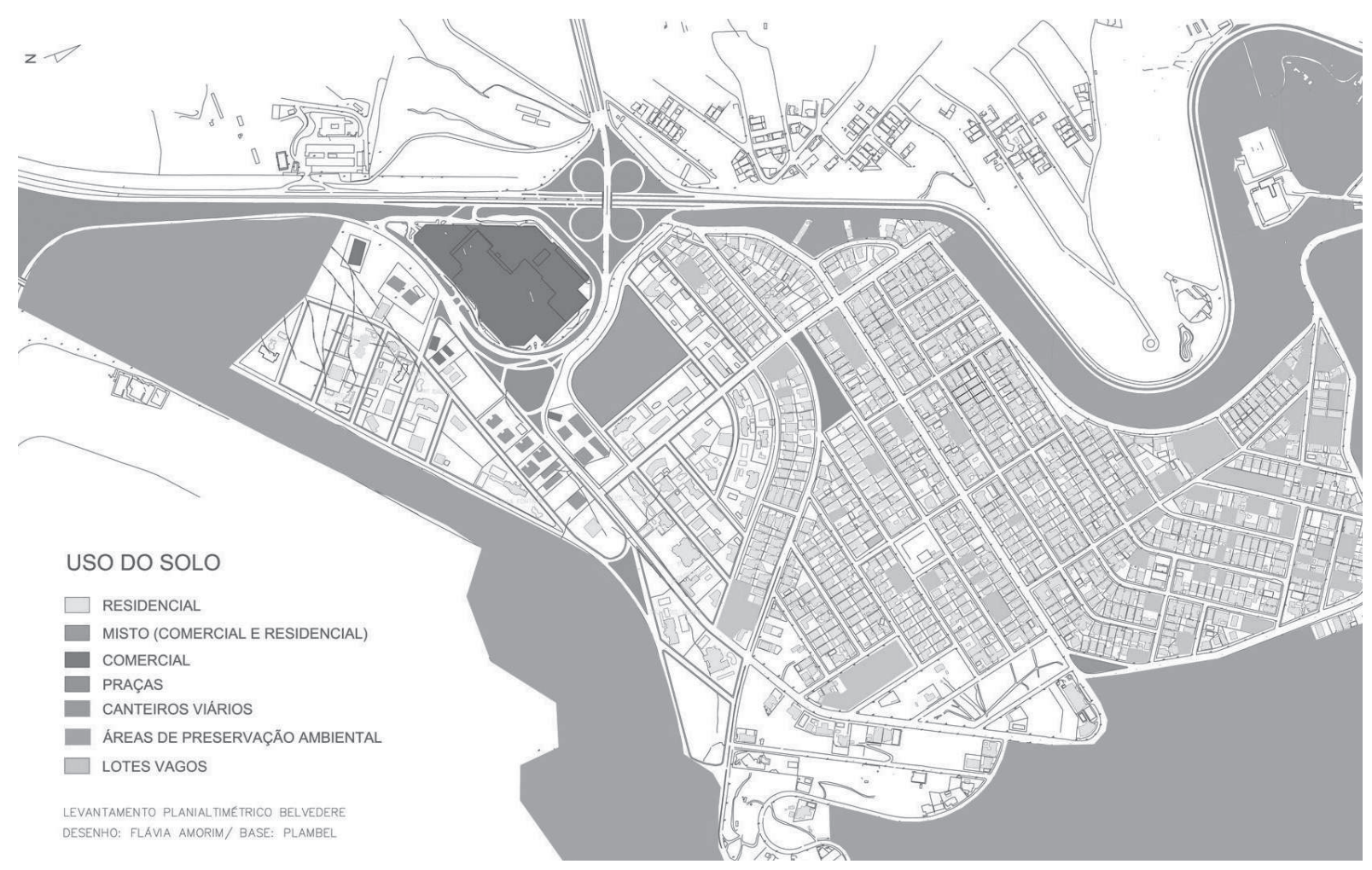

Figura 2: Mapa Uso do solo

Desenho: Flávia Amorim, 2006

Devido a esta diferenciação de usos, os fluxos também se divergem, á área mais antiga, essencialmente residencial, é constituída essencialmente por vias locais de pouco movimento, já na nova ocupação temos uma via coletora e uma arterial que concentram o fluxo de veículos e pedestres ao concentrar o comércio local da região.

O mapa de figura e fundo mostra a diferença de adensamento entre a área de ocupação horizontal e a área de ocupação vertical, demonstrando que, em planta, as áreas de ocupação vertical apresentam uma densidade menor.

mapa de configuração Morfológica demonstra a intensidade das áreas verdes encontrada na região do Belvedere I, devido à massa verde nos quintais dos lotes e lotes vagos, podemos 


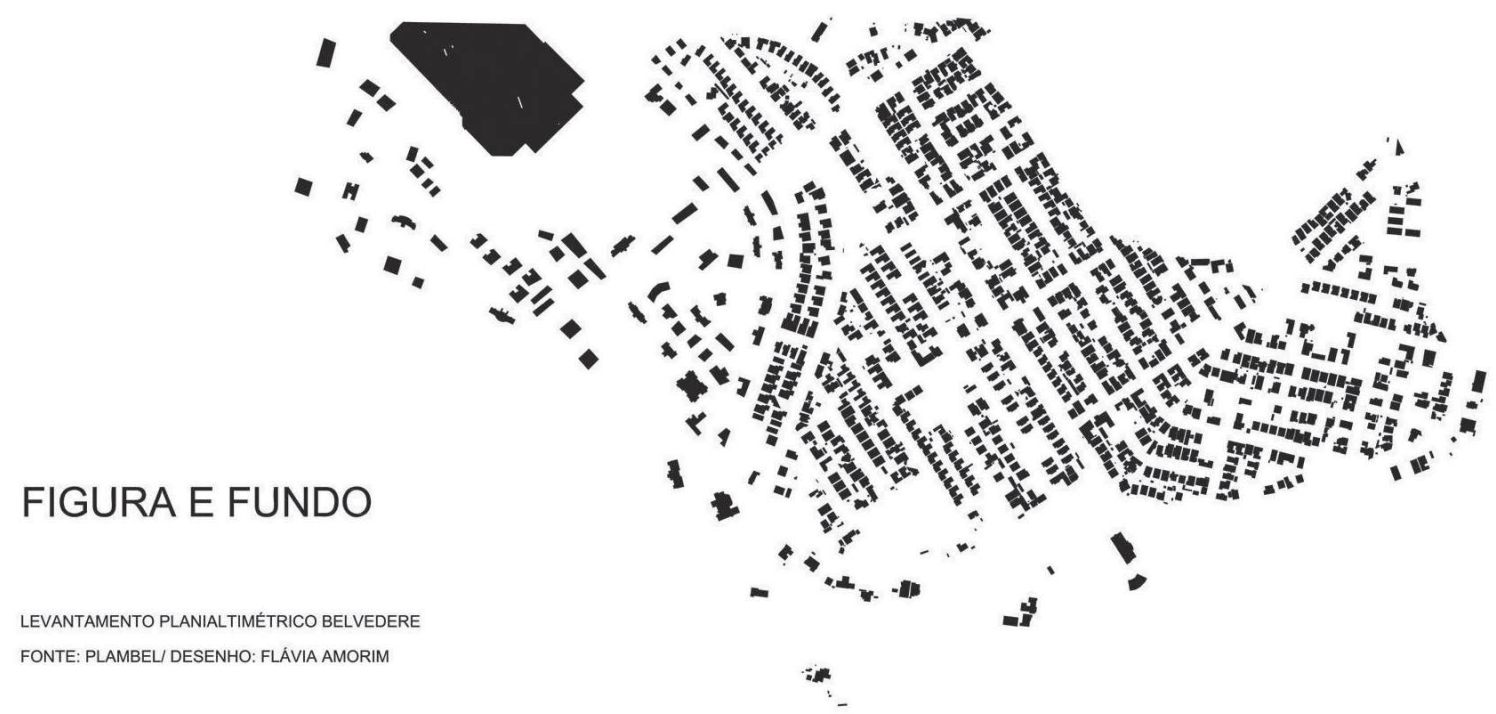

Figura 3: Figura e fundo

Desenho: Flávia Amorim, 2006

perceber a mesclagem do verde com área edificada, enquanto que no novo loteamento, a massa edificada assume uma porção homogênea em contraponto com a massa vegetada, encontrada em canteiros e praças com tratamento paisagístico.

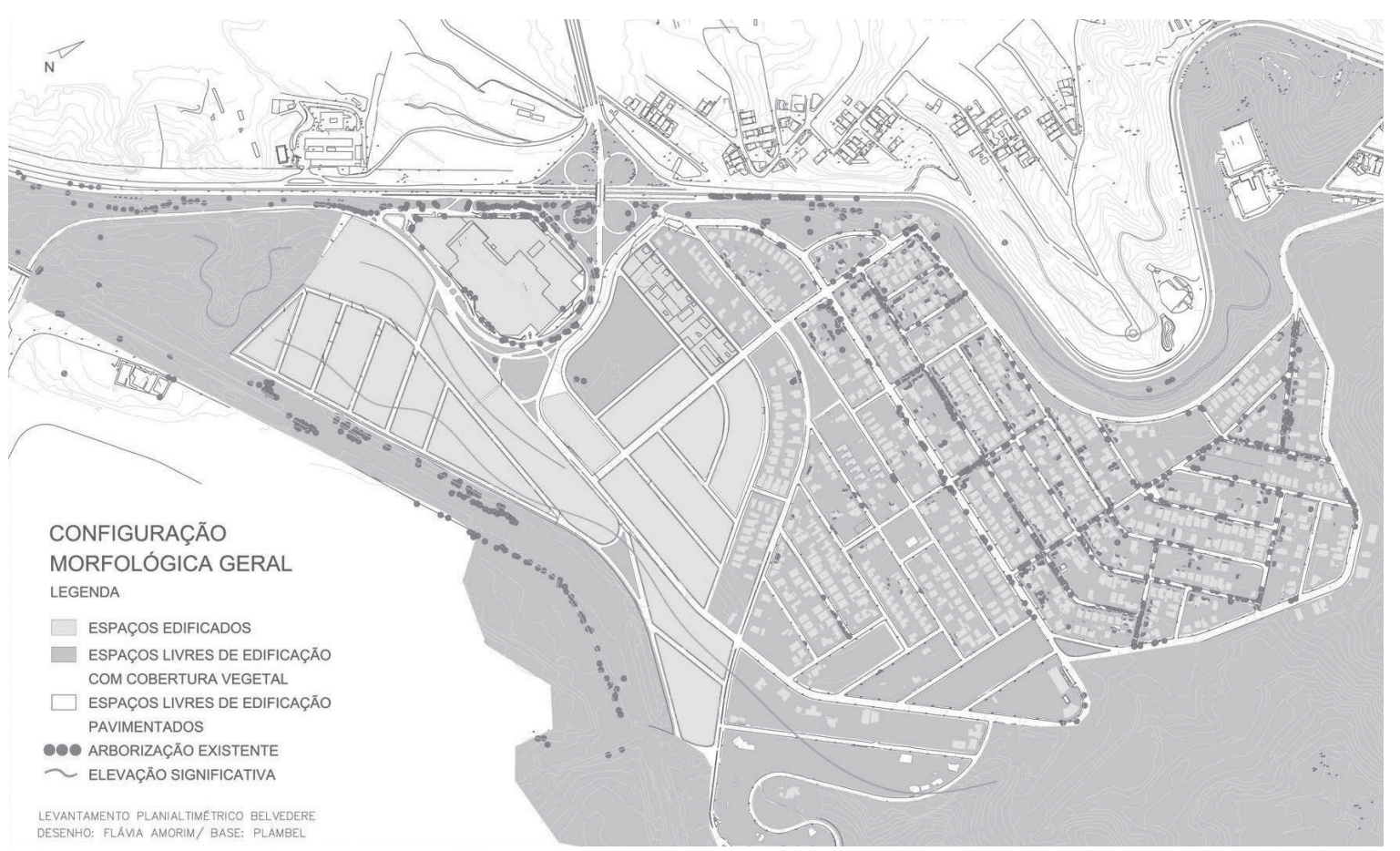

Figura 4: Mapa Configuração morfológica

Desenho: Flávia Amorim, 2006

A relação entre espaços livres públicos, espaços livres privados e espaços edificados no Belvedere é muito diferenciada. As áreas livres públicas estão em maior concentração na área de novas edificações evidenciando a baixa oferta de praças e parques no bairro, no Belvedere I e II é encontrada maior área livre privada, devido à existência de quintais e áreas de lazer das casas, enquanto que o Belvedere III não possui espaço livre privado com uma ocupação de $100 \%$ do terreno torna a área totalmente edificada. 


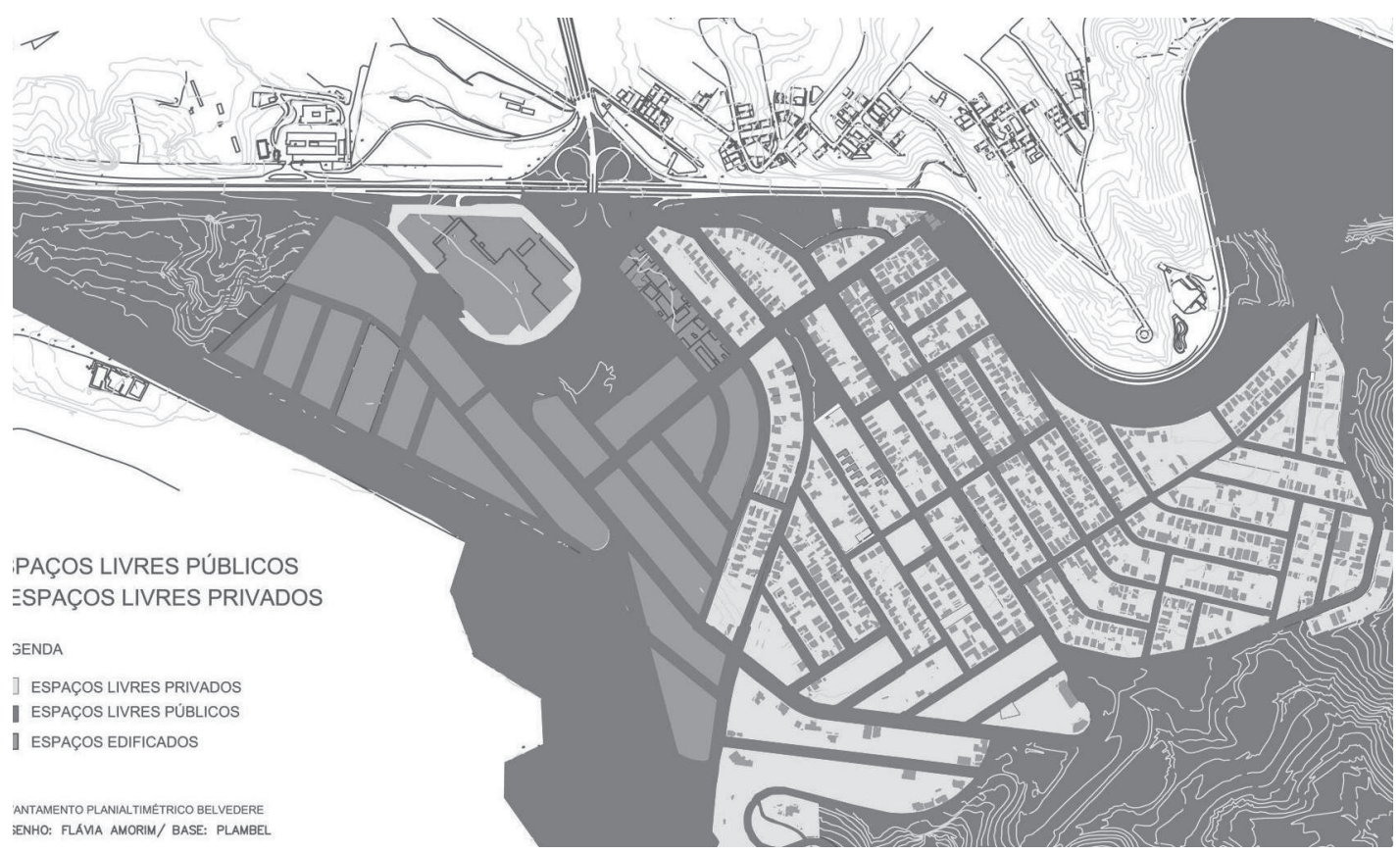

Figura 5: Mapa Espaços Livres Públicos x Espaços Livres Privados Desenho: Flávia Amorim, 2006

\section{4 - Na escala da rua: tipos morfológicos existentes}

Os critérios que definem os tipos morfológicos encontradas no Belvedere conjugam aspectos relativos ao processo de ocupação do bairro, aos padrões edilícios característicos de cada fase, às atividades existentes, ao perfil fundiário, aos padrões de ocupação do lote, às relações existentes entre os espaços livres privados e à configuração morfológica geral.

Cruzando estes aspectos delineamos, até o momento, cinco tipos básicos, cuja distribuição espacial está ilustrada no mapa de localização das tipologias (Figura 40) e cuja descrição se segue:

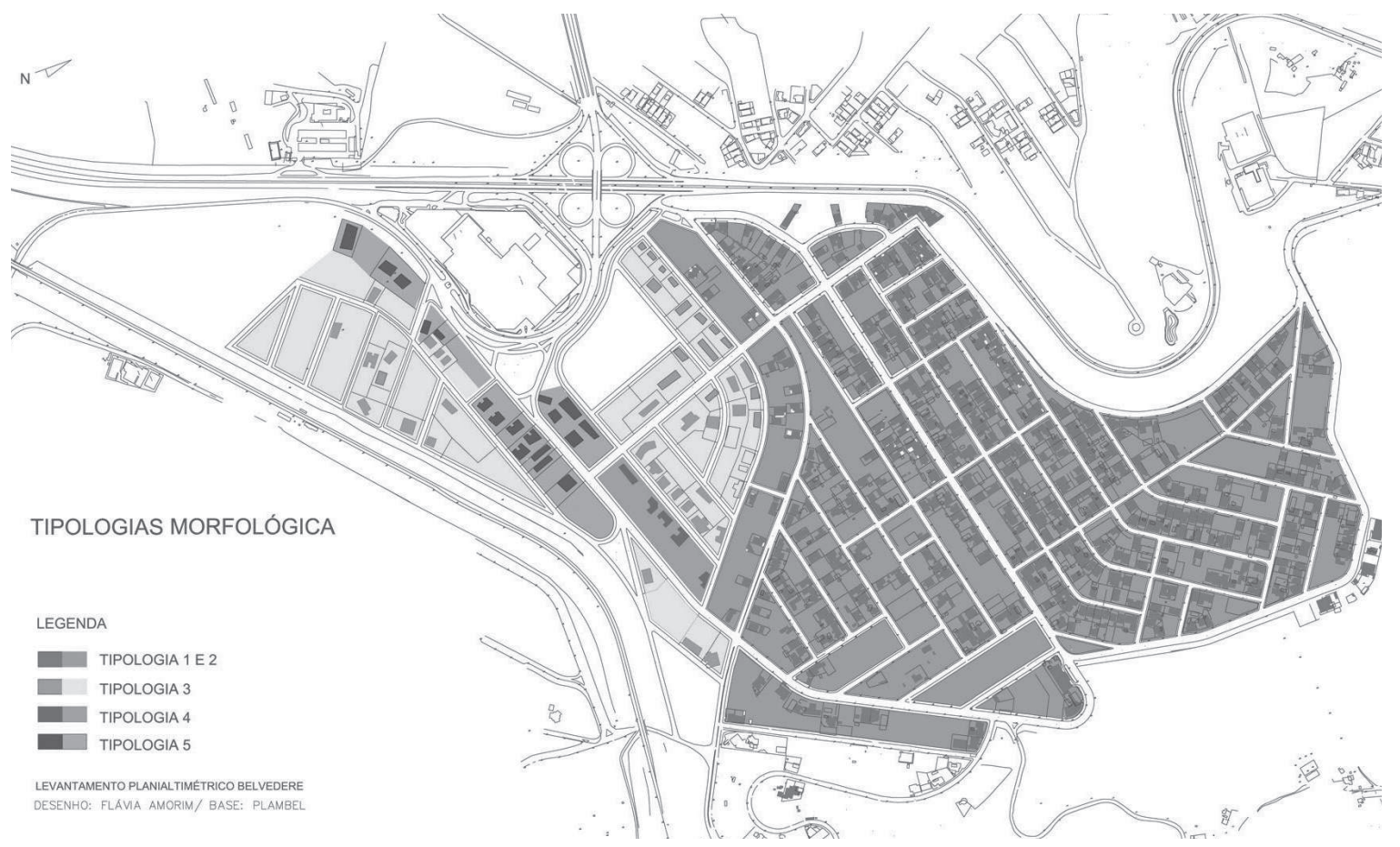

Figura 6: Mapa Localização dos tipos

Desenho: Flávia Amorim, 2006 


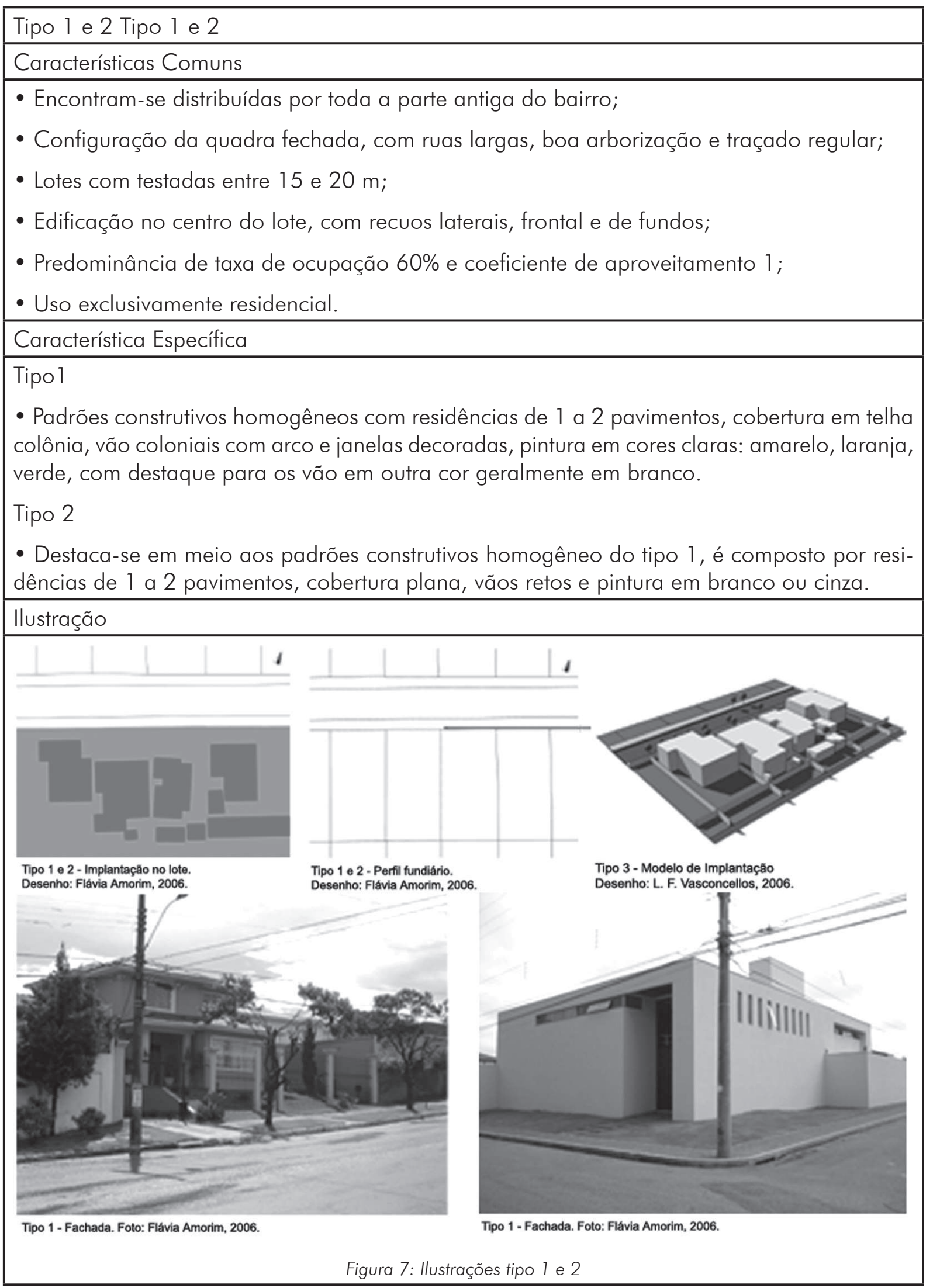


Tipo 3

- Apresenta-se na área de ocupação recente;

- Configuração da quadra fechada, com ruas largas, boa arborização e traçado regular;

- Edificação sob pilotis no centro do lote, com recuos laterais, frontal e de fundos;

- Predominância de taxa de ocupação 15\% e coeficiente de aproveitamento 3;

- Uso predominantemente residencial;

- Lotes com testadas entre 15 e 20 m, agrupados em 2 ou mais formando testadas de $30 \mathrm{~m}$ ou mais;

- Padrões construtivos homogêneos com edifícios de 18 pavimentos em média.

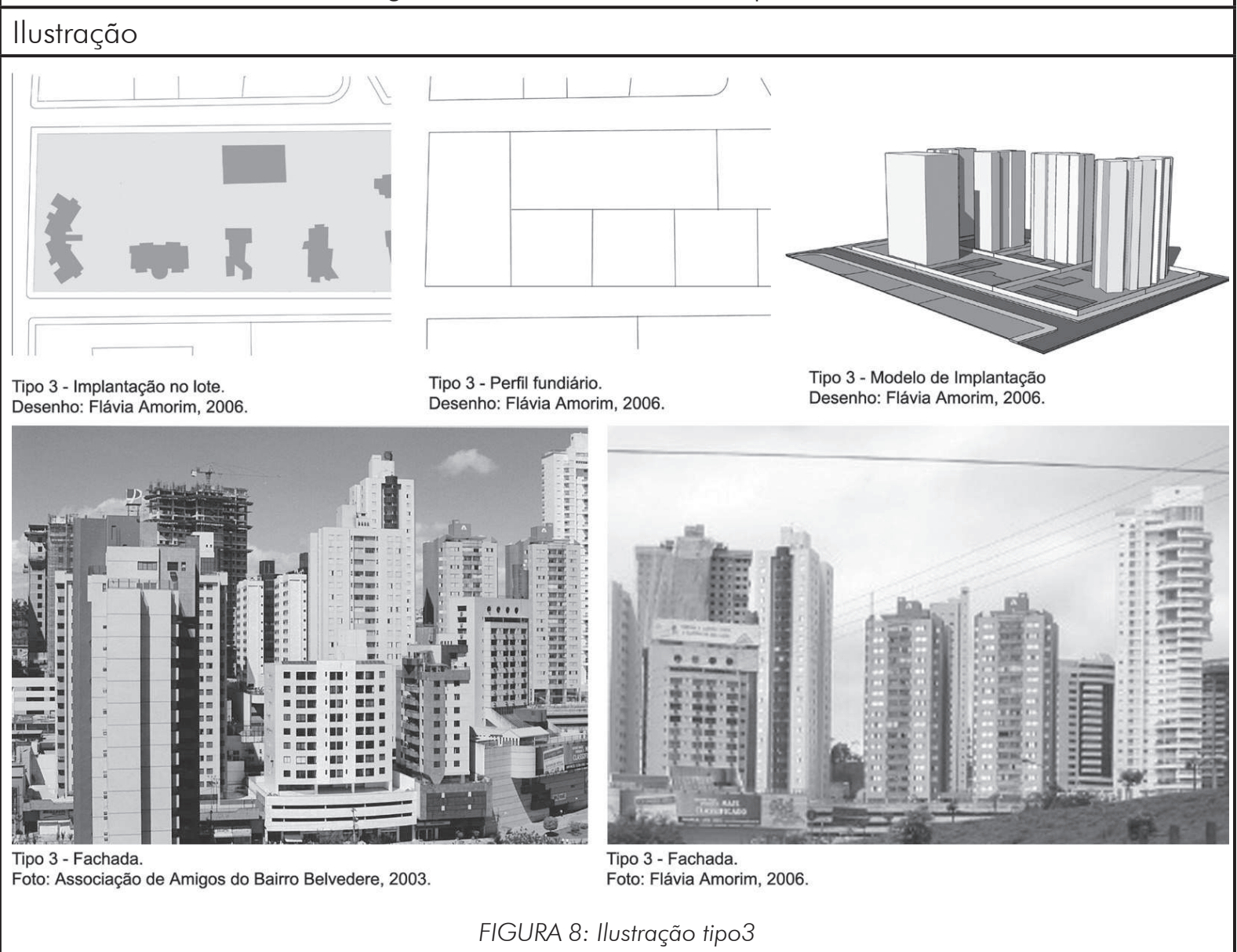


Tipo 4

- Apresenta-se apenas na Rua Juvenal de Melo Senra, na área de ocupação recente;

- Configuração da quadra fechada, com ruas largas, boa arborização e traçado regular;

- Lotes com testadas entre 15 e 20 m, agrupados em 2 ou mais formando testadas de 30 m ou mais;

- Predominância de taxa de ocupação 15\% e coeficiente de aproveitamento 3;

- Uso predominantemente residencial;

- Edificação com garagem elevada que ocupam 100\% da área de projeção do lotes, sem afastamentos, o edifício se desenvolve sob a garagem, sob pilotis no centro do lote, com recuos laterais, frontal e de fundos; Padrões construtivos homogêneos com edifícios de 18 pavimentos em média.

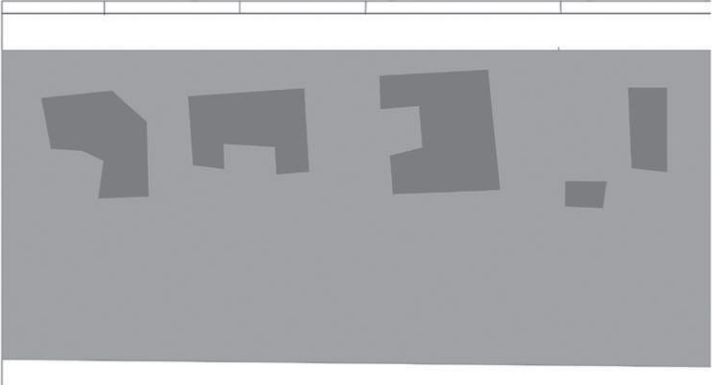

Tipo 4 - Implantação no lote. Desenho: Flávia Amorim, 2006.
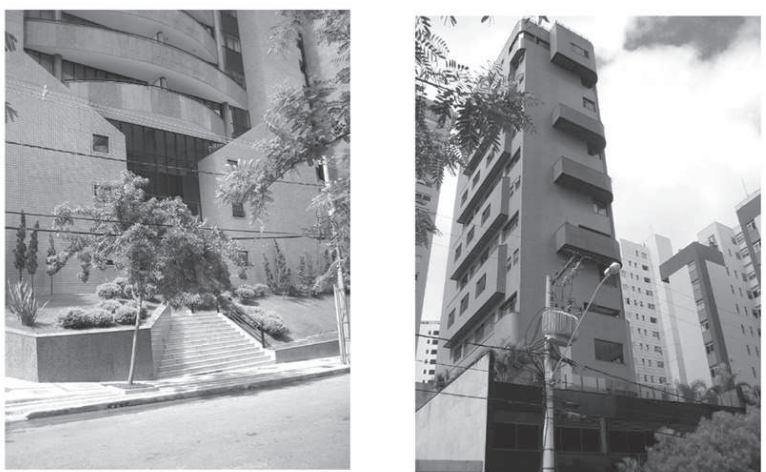

Tipo 4 - Fachada. Foto: Flávia Amorim., 2006

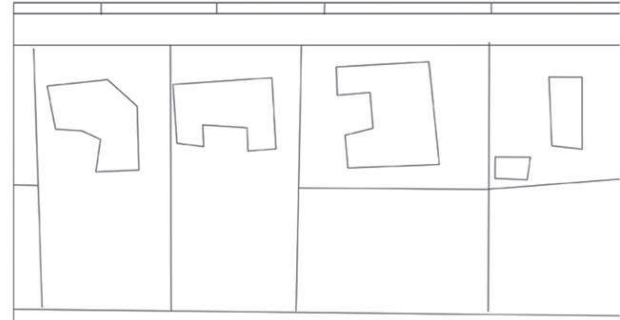

Tipo 4 - Perfil fundiário. Desenho: Flávia Amorim, 2006.

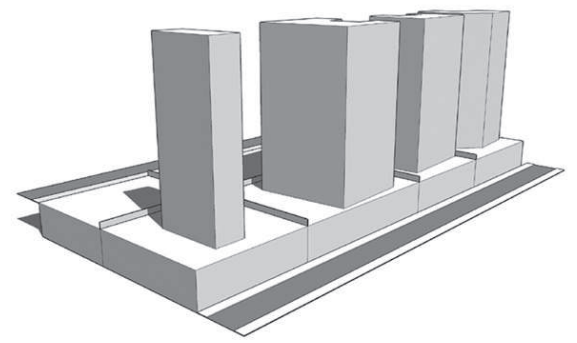

Tipo 4- Modelo de Implantação Desenho: L. F. Vasconcellos, 2006. 


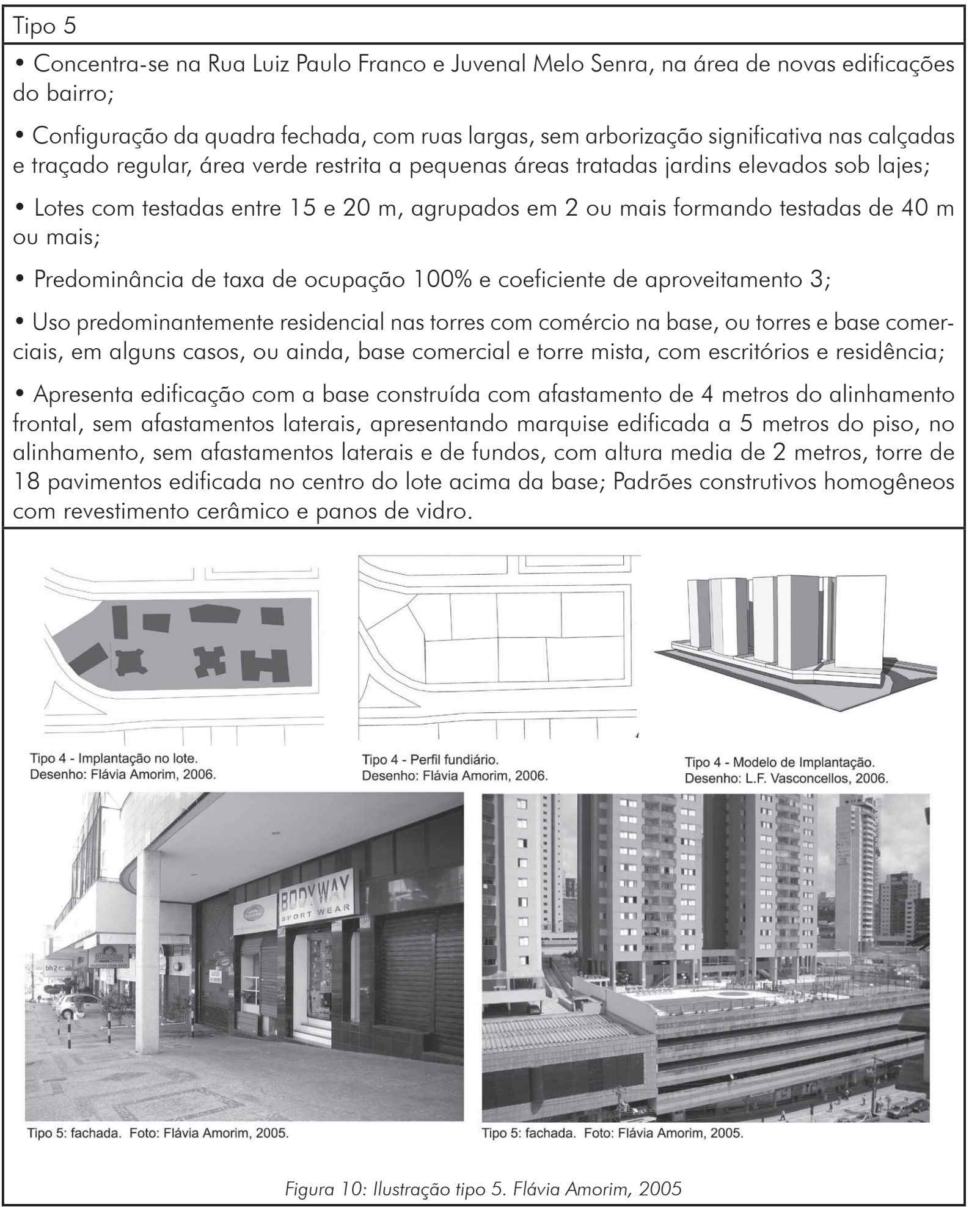

\section{4 - Considerações finais}

\section{Dos conceitos gerais temos:}

Tipologia Edilícia - sucessão histórica de um determinado tema (habitação, teatro, galerias comerciais, templos, escolas, hospitais, praças, entre outros), é um elemento determinante da cidade moderna e contemporânea; 
Modelo - é um objeto que deve ser copiado, repetido de foram idêntica e exata, todas as características são definidas com precisão;

Tipo - é um objeto que admite alterações;

Morfologia Urbana - constitui um método de análise que investiga os componentes físicoespaciais (lotes, ruas, tipologias edilícias e áreas livres) e sócio-culturais (usos, apropriação e ocupação) da forma urbana e como eles variam em função do tempo.

\section{Da aplicação entendemos}

No caso em estudo a ocupação é de alta renda e acontece buscando os modelos de edificações preconizados por São Paulo e Rio de Janeiro, mas que no caso de Belo Horizonte são reduzidos à escala e demanda local. $O$ acabamento dos edifícios, a verticalização, a oferta de equipamentos de lazer segue a uma mesma tendência do mercado nacional de imóveis.

Um dos fatores identificados que determinam esta redução do modelo implantado é a área disponível, muito menor em Belo Horizonte, provocando um adensamento maior. Outro ponto é o poder aquisitivo do mineiro muito mais baixo que o do carioca ou paulista, enquanto que no Morumbi o valor para venda de um apartamento de $200 \mathrm{~m}^{2}$ varia entre um milhão e quinhentos mil reais a dois milhões de reais, na Barra da Tijuca, encontra-se valores de um milhão a 1 milhão e quinhentos mil, em Belo Horizonte o valor gira em torno de seiscentos a novecentos mil reais.

Este estudo identifica os pontos de análise importantes no entendimento das características do bairro. A associação da visão científica à percepção do espaço do ponto de vista do usuário permite a sobreposição da interpretação científica do profissional que visa desenho, projeto e ação com os aspectos culturais inerentes á sociedade, possibilitando uma análise mais próxima do real. Enfim, entendemos que pesquisar a cidade, sua dinâmica, sua formação e refletir sobre os impactos de sua expansão é uma forma de tentar influenciar o projeto urbano e seu reflexo na formação da paisagem. Com este trabalho pretendemos iniciar um estudo aprofundado e reflexivo da paisagem urbana de Belo Horizonte, por meio da análise de expansão e ocupação recente do bairro Belvedere.

\section{Notas}

(1) A paisagem urbana é entendida aqui segundo o conceito de Lamas como "parte de um território ou país que a natureza apresenta ao observador", portanto no sentido da descrição dos aspectos exteriores de uma realidade. (LAMAS, José M. R. G. Morfologia urbana e o desenho da cidade. Lisboa: Fundação Calouste Gulbekian, 1992).

(2) Referências a Rossi extraídas do livro de LAMAS, José M. R. G. Morfologia urbana e o desenho da cidade. Lisboa: Fundação Calouste Gulbekian, 1992.

(3) Extraído do texto de ARGAN, Giulio Carlo. Projeto e destino. Tradução de Nanos Bagno. 1 ed. São Paulo: Ática, 2000, p. 65-70.

(4) ROSSI, Aldo. Consideraciones sobre la morfologia urbana y la tipologia contructiva. In: Aspetti e problemi della tipologia edilizia. Venezia: Cluva, 1964. p. 127-137.

(5) ROSSI, Aldo. Arquitetua da cidade. Martins Fontes: São Paulo, 1995. p. 24.

(6) ROSSI, Aldo. Consideraciones sobre la morfologia urbana y la tipologia contructiva. In: Aspetti e problemi della tipologia edilizia. Venezia: Cluva, 1964. p.127-137.

(7) LAMAS, José M. R. G. Morfologia urbana e o desenho da cidade. Lisboa: Fundação Caloute Gulbekian, 1992.

\section{Bibliografia}

ARGAN, Giulio Carlo. Projeto e destino. Tradução de Nanos Bagno. 1 ed. São Paulo: Ática, 2000. p. 65-70.

BELO HORIZONTE. Prefeitura Municipal. Lei de Uso e Ocupação do Solo do Município de Belo Horizonte. Lei n. 4.034 de 25.03.85. 
EPPINGHAUS, Annie G. Influência do projeto no processo de apropriação dos espaços públicos em áreas residenciais: O caso da barra da Tijuca. 2005. Dissertação (Mestrado) - Proarq, Rio de Janeiro, 2005.

LAMAS, José M. R. G. Morfologia urbana e o desenho da cidade. Lisboa: Fundação Calouste Gulbekian, 1992.

MONTANIER, Josep Maria. Depois do movimento moderno: Arquitetura da segunda metade do século XX. Barcelona: Gustavo Gili, 2001.

ROSSI, Aldo. Consideraciones sobre la morfologia urbana y la tipologia contructiva. In: Aspetti e problemi della tipologia edilizia. Venezia: Cluva, 1964. p.127-137. Gili, 1977

. Tipologia, manualística y arquitectura. In: Para uma arquitectura de "tendenza". Barcelona: Ed. Gustavo . Arquitetua da cidade. São Paulo, Martins Fontes: 1995.

TÂNGARI, Vera Regina. Um outro lado do Rio. 1999. 357 p. Tese (Doutorado) - Faculdade de Arquitetura e Urbanismo Universidade de São Paulo, São Paulo, 1999. 